\title{
Articular cartilage: amphoteric nature and interfacial energy
}

\author{
Aleksandra Mreła ${ }^{1}$ and Zenon Pawlak ${ }^{2,3 *}$ \\ ${ }^{1}$ Kujawy and Pomorze University in Bydgoszcz, Faculty of Technology, Torunska 55-57, Bydgoszcz, 85-023, Poland \\ ${ }^{2}$ Tribochemistry Consulting, Salt Lake City, UT 84117, USA \\ ${ }^{3}$ University of Economy, Biotribology Laboratory, Garbary 2, 85-229 Bydgoszcz, Poland
}

\begin{abstract}
The amphoteric nature of phospholipid bilayers membrane with the amino- and phosphate functional groups is affected by solution pH and was verified by the electrophoretic method. We examined the characteristics of the spherical lipid bilayers form from phosphatidylcholine articular cartilage surface using a combination of interfacial energy and friction tests. The observations have led to the conclusions that cartilage the interfacial energy is expressing amphoteric nature with isoelectric point (IEP) "bell-shape curve" significantly dependent on $\mathrm{pH}$ range 0 to 6.5 and stable range 6.5 to 9.0.
\end{abstract}

\section{Introduction}

The hydrophilic surface of articular cartilage has been attracted to bilayers of phospholipids, to generate a hydrophilic multibilayer (Figurela) [1,2]. The 'smart surface' of articular cartilage is covered by bilayers of phospholipids and has $\sim 0^{\circ}$ wettability when is wet (hydrophilic) and $104^{\circ}$ wettability when the surface is air-dry and turn hydrophobic (Figure1b) [3].

In chemical analysis (SAPL) bilayers study, phosphatidylcholine was found to be the major phospholipid class, constituting $41 \%$ of all phospholipids, whereas phosphatidylethanolamine and sphingomyelin accounted for $27 \%$ and $32 \%$, respectively, of total phospholipids, Figure 2 [4]. Their configuration renders phospholipid molecule surface active and capable of acting at interfaces. Surface activity is a property of PLs to locate (adsorb) at an interface (surface) resulting imbalance of forces at the interface impart additional surface energy, termed interfacial [1]. These desirable properties include load-bearing lubricants in the joints, which Hills named surface-active phospholipid (SAPL).

SAPL occurs in synovial fluid (SF), its list of components is much the same but in different proportion. In Kosinska, et al. [5] study, the major phospholipid classes in SF were phospholipids that contained phosphatidylcholine (67\%), sphingomyelin (17\%), and
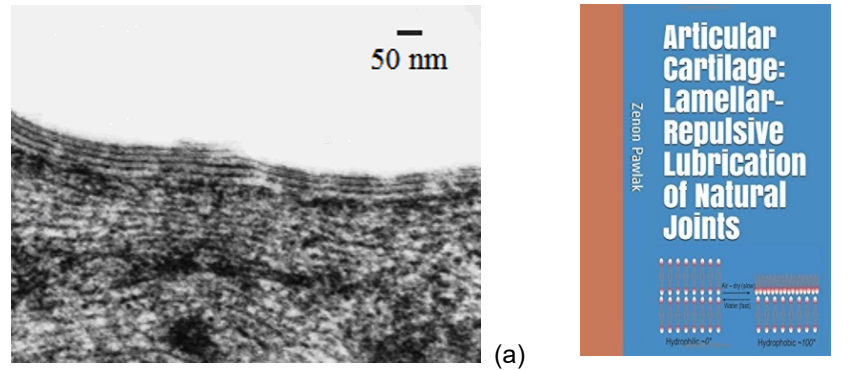

(b)

Figure 1. (a) The electron microscopy of the articular cartilage of a human knee with surface-active phospholipid (SAPL) bilayers [2], and (b) book cover page 'Articular cartilage: Lamellar repulsive-lubrication of natural joints' [3]

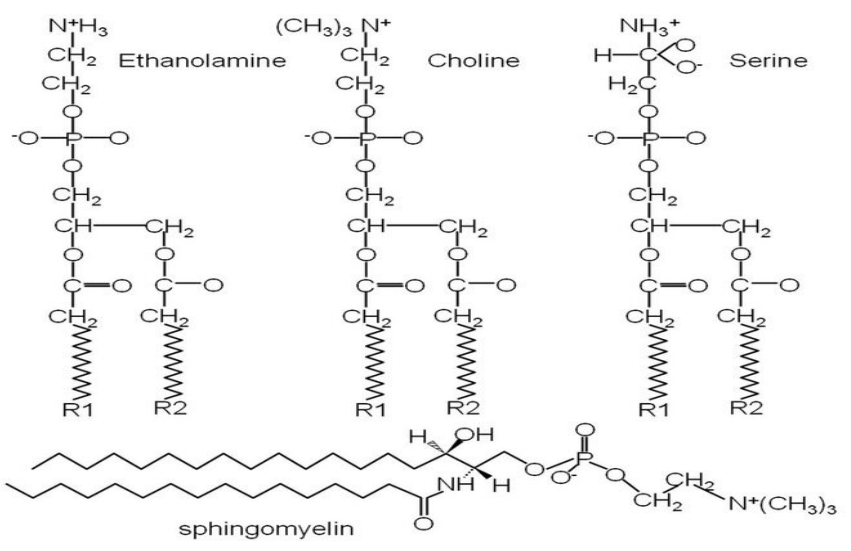

Figure 2. Molecular configuration of the major membrane lipids: Phosphatidylcholine (PC); Phosphatidylethanolamine (PE); Phosphatidylserine (PS) and Sphingomyelin (SM)

lysophosphatidylcholine (10\%) - whereas phosphatidylethanolamine constituted only $2.5 \%$ of total phospholipids.

In this paper, the chemical and physical properties of the cartilage surfaces, the interfacial energy of the spherical lipid bilayers form from phosphatidylcholine, and the friction coefficient between (AC/AC) was found to respond in the amphoteric manner as the $\mathrm{pH}$ varied and was investigated.

\section{Methods and materials}

\section{Materials}

The articular cartilage specimens were collected from bovine knees aged 15-20 months. Osteochondral plugs, of 5 and $10 \mathrm{~mm}$ in diameter,

${ }^{\star}$ Correspondence to: Zenon Pawlak, Tribochemistry Consulting, Salt Lake City, UT 84117, USA, E-mail: zpawlak@xmission.com

Key words: amphoteric articular cartilage, interfacial energy, friction coefficient

Received: July 13, 2018; Accepted: July 24, 2018; Published: July 27, 2018 
were harvested from lateral and medial femoral condyles. The cartilage discs were cut into $3-\mathrm{mm}$ plugs with underlying bone. The cartilage discs were then glued to the disc and pin stainless steel surfaces, and friction tests were conducted in the universal the Britton-Robinson buffer solution.

\section{Friction test}

The measurements were performed using a sliding pin-on-disc tribotester T-11 manufactured by the NIST Research, Radom, Poland. The tests were conducted at room temperature, at a speed of $1 \mathrm{~mm} / \mathrm{s}$ during 5 minutes, and under a load of $15 \mathrm{~N}(1.2 \mathrm{MPa})$ which correspond to the physiological lubrication condition. Prior to the friction tests, the lubricants were prepared using the Britton-Robinson buffer solution, and their $\mathrm{pH}$ values were measured. The friction coefficients measurements of cartilage/cartilage tribopair were carried out over the $\mathrm{pH}$ range between 1.0 and 9.5.

The microelectrophoretic apparatus and the method are described in [6-8].

\section{Results and discussion}

The predominant component AC of PLs that contained phosphatidylcholine, and sphingomyelin the molecular configuration of which is shown in Figure 2, in its commonly occurring form quaternary ammonium ion (QA) $\left[\left(\mathrm{CH}_{3}\right)_{3} \mathrm{~N}^{+}\right.$-]. QA is strongly positively charged at $\mathrm{pH} 7.4$ of biological tissues. Being positively charged possesses strong adsorption ability to most biological surfaces negatively charged or hydrophilic [1]. At $\mathrm{pH} 7.4$, the concentration of hydroxide ions is high enough to interact with quaternary ammonium ion (QA), $\left(\mathrm{CH}_{3}\right)_{3} \mathrm{~N}^{+}$) with association constant, $\mathrm{K}_{\text {ass }} \sim 5 \times 10^{5}[9,11]$.

$$
\left[\left(\mathrm{CH}_{3}\right)_{3} \mathrm{~N}^{+}-\right]+(-\mathrm{OH})=\left(\mathrm{CH}_{3}\right)_{3} \mathrm{~N}^{+}(-\mathrm{OH}) \quad \mathrm{K}_{\mathrm{ass}} \sim 5 \times 10^{5}
$$

The interfacial energy method was used in this study to address the question of how the interfacial surface energy of amphoteric phospholipidic bilayer surface affects the extremely low-friction coefficient of natural articular cartilage [4,7]. Under our mechanism, the articular surface is hydrophilic and negatively electrically charged. It is consistent with the results from the study of natural joints [3] and surfaces of multilayers of weak polyelectrolyte (hyaluronic acid/poly (L-lysine) [8]. A lipid molecule is a pH-sensitive amphoteric zwitterion. A study on adsorption of the $\left(-\mathrm{H}^{+}\right)$and $\left(-\mathrm{OH}^{-}\right)$ions over the $\mathrm{pH}$ range 0 to 11 should demonstrate that it effectively could reproduce properties of a living membrane. In the measurements, bilayer lipid membranes were used in the form of spherical lipid bilayers.

\section{The interfacial energy vs. $\mathrm{pH}$}

Phospholipids, amphoteric molecules containing both positive and negative charges depending on the functional groups, is affected by the solution's $\mathrm{pH}$. At a low $\mathrm{pH}$, PLs amino group occurs in the protonated $\left(-\mathrm{NH}_{3}^{+}\right)$(phosphatidylethanolamine) or $\left(\mathrm{CH}_{3}\right)_{3} \mathrm{~N}^{+}$) form (phosphatidylcholine) and the phosphate group $\left(-\mathrm{PO}_{4} \mathrm{H}\right)$ occurs in its molecular form; a situation that is characterized by a low interfacial energy. As the $\mathrm{pH}$ of the solution is increased, the amino groups begin to lose partially their charge $\left(-\mathrm{NH}_{3}^{+} \rightarrow-\mathrm{NH} 2\right)\left(\right.$ or $\left.\left(\mathrm{CH}_{3}\right)_{3} \mathrm{~N}^{+} \mathrm{OH}\right)$ and the $\left(-\mathrm{PO}_{4} \mathrm{H}\right)$ groups begin to lose partially their proton $\left(-\mathrm{PO}_{4} \mathrm{H} \rightarrow-\mathrm{PO}_{4}\right.$ ), this resulting in an increase in the surface energy with a magnitude approaching a maximum. This maximum would occur, as shown in Figure 3, at the isoelectric point, $I P$ which corresponds to the $\mathrm{pH}$ at which PLs or surface carriers have no net electrical charge, or when the negative and positive charges become equal [1].

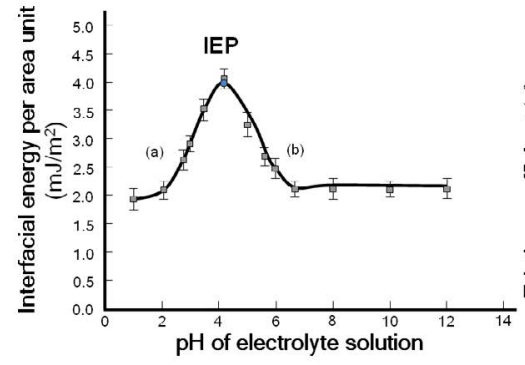

(a)

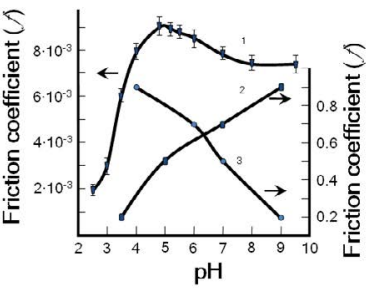

(b)
Figure 3. (a) Effect of pH buffer solution on the interfacial energy spherical lipid bilayers formed by phosphatidylcholine and (b) the cartilage friction coefficient. Experimental values of the interfacial energy taken from (Petelska and Figaszewski [10])

The isoelectric point, IEP, is at a pH of 4.12 (a) (Left-hand branch of the curve) $\mathrm{pH} 1.0$ to $\left.\left.4.12\left(\mathrm{CH}_{3}\right)_{3} \mathrm{~N}^{+}\right) \rightarrow\left(\mathrm{CH}_{3}\right)_{3} \mathrm{~N}^{+} \mathrm{OH}\right)$; Maximum point of curve ( $\mathrm{pH} 4.15, \mathrm{IEP},\left(\mathrm{CH}_{3}\right)_{3} \mathrm{~N}^{+}\left(\mathrm{CH}_{2}\right)_{2}$ $\left.\mathrm{PO}_{4}^{-} \mathrm{R}_{1} \mathrm{R}_{2}\right)$; (b) Right-hand branch of the curve $\mathrm{pH} 4.12$ to $6.6\left(-\mathrm{PO}_{4} \mathrm{H} \rightarrow-\mathrm{PO}_{4}^{-}\right)$. The friction changes, as the $\mathrm{pH}$ is raised toward to curve's maximum as can be expressed by reactions progressing on the cartilage surface: (curve 1) $\left.\left.\left(\mathrm{CH}_{3}\right)_{3} \mathrm{~N}^{+}\right) \rightarrow\left(\mathrm{CH}_{3}\right)_{3} \mathrm{~N}^{+} \mathrm{OH}^{-}\right)$and after the isoelectric point, IEP $\left(-\mathrm{PO}_{4} \mathrm{H} \rightarrow-\mathrm{PO}_{4}^{-}\right)$. For support our experiment, multilayers of non-amphoteric (poly (L-lysine)/hyaluronic acid) [8] (curve 2) $\left(\mathrm{L}-\right.$-lysine $\left(-\mathrm{NH}_{3}^{+} \rightarrow-\mathrm{NH}_{2}\right)$ (curve 3) hyaluronic acid (- $\left.\mathrm{COOH} \rightarrow-\mathrm{COO}^{-}\right)$; (Curve 1) friction coefficient (\%) standard deviation (SD) 9 to 14 .

In this situation, the resulting surface would become less hydrophobic with a lower friction coefficient $(f)$ [8]. The maximum interfacial energy $\left(\gamma_{\max }\right)$ values of the PC and PS membrane were found to be 3.53 and $2.93 \mathrm{mN} / \mathrm{m}$ at the $\mathrm{pH}$ of 4.1 and 3.80 , respectively. The $\mathrm{pH}$ of the solution influences changes in electric charge of the membrane due to variations in the acid-base equilibrium of the functional groups $\left(-\mathrm{NH}_{2}\right.$ or $\left.\left(\mathrm{CH}_{3}\right)_{3} \mathrm{~N}^{+}\right)$and $\left(-\mathrm{PO}_{4} \mathrm{H}\right)$ of the membrane.

The effect of $\mathrm{pH}$ on the interfacial energy of spherical lipid bilayers formed from sphingomyelin (SM) has been described previously by Petelska and Figaszewski [9]. At pH 7.4 concentration ions $(-\mathrm{OH})$ which are the very strong base to discharge $\mathrm{Me}_{3} \mathrm{~N}^{+}+(-\mathrm{OH})=\mathrm{Me}_{3} \mathrm{~N}^{+}$ $(-\mathrm{OH})$, and to keep cartilage surface negatively charged from functional group $\left(-\mathrm{PO}_{4}^{-}\right)$. Biosurface wettability can be measured relative to the differences in the charge density of functional amino-, and phosphate $\left(-\mathrm{NH}_{2}\right.$, or $\left.\left(\mathrm{CH}_{3}\right)_{3} \mathrm{~N}^{+}\right)$and $\left.-\mathrm{PO}_{4} \mathrm{H}\right)$ groups. In this regard, the wettability and interfacial energy of surfaces that are characterized by charged anionic phosphate $\left(-\mathrm{PO}_{4}^{-}\right)$) groups are lower than those of surfaces carrying molecular constituents $\left(-\mathrm{PO}_{4} \mathrm{H}\right)$ [7-11].

Thephosphatidylcholine(PC)belongstoamphotericpolyelectrolytes with the amine $\left.\left(\mathrm{CH}_{3}\right)_{3} \mathrm{~N}^{+}\right)$and phosphate $\left(-\mathrm{PO}_{4} \mathrm{H}\right)$ functional groups. The maximum on both curves was at the isoelectric point ( $\mathrm{pH} 4.12$ ) for PLs (PC) (pure phospholipid), and at $\mathrm{pH} 4.5$ for cartilage (a mixture of phospholipids and other biomolecules) (Figure 3). This slow decrease in $(f)$ after IEP suggests the presence of other anionic macromolecules besides the phospholipid. The maximum interfacial energy $\left(\gamma_{\max }\right)$ was found at $3.53 \mathrm{mJm}^{-2}$, while on the abscissa the $\mathrm{pH}$ was 4.12 . On the upper graph of Figure 3 (curve 1), the maximum friction coefficient of 0.009 occurred when the $\mathrm{pH}$ was 4.7 . At a $\mathrm{pH}$ of about 2 , the amino groups of PLs occur in the protonated form $\left.\left(\mathrm{CH}_{3}\right)_{3} \mathrm{~N}^{+}\right)$, while $-\mathrm{PO}_{4} \mathrm{H}$ is in its molecular form. When the $\mathrm{pH}$ of the solution increases, the amino group begins to lose its proton $\left(-\mathrm{NH}_{3}+\rightarrow-\mathrm{NH}_{2}\right)$, leading to an increase in the interfacial energy towards a maximum value at the isoelectric point (IEP), amphoteric while the $-\mathrm{PO}_{4} \mathrm{H}$ group also tends to gradually lose its proton $\left(-\mathrm{PO}_{4} \mathrm{H} \rightarrow-\mathrm{PO}_{4}^{-}\right)$. At IEP, both surface constituents would carry no net electric charge (i.e., the negative and positive charges would be equal) [6]. With a continual increase in the $\mathrm{pH}$, after IEP, the amino group would gradually lose its charge, while the $-\mathrm{PO}_{4} \mathrm{H}$ group loses its 
proton $\left(-\mathrm{PO}_{4} \mathrm{H} \rightarrow-\mathrm{PO}_{4}^{-}\right)$, leading to a negatively charged surface with decreased interfacial energy and decreased friction coefficient $(f)$.

\section{Amphoteric nature of cartilage surface}

Some organic compounds, e.g., phospholipids and amino acids are amphoteric molecules that contain both acidic and basic groups. The $\mathrm{pH}$ at which the molecule charge is zero or a neutral is known as the molecule's isoelectric point, IEP. A neutral molecule is named as a zwitterion. Zwitterions, formerly called dipolar ions, are ions with both a negative and positive charges. Phosphatidylethanolamine one of the components of cartilage is shown in it's cationic, anionic and zwitterion forms (Figure 4).

The amphoteric cartilage's surface behavior is a physical phenomenon in biological lubrication. However, there is a lack of knowledge on amphoteric phospholipids bilayers and on overcoming friction in cartilage joints. An important difference between biological and man-made lubrication systems is that in the former the lubricant is chemically attached to the surface of, for example, a cartilage joint. The amphoteric phospholipids (PLs) are the main solid-phase components on the negatively charged surface of articular cartilage (AC) which are responsible for the biological lubrication mechanism [6]. It has been well established that the PL bilayers mechanism, which essentially is based on the surface amorphous layer (SAL) surrounded by a 0.155 $\mathrm{M}$ electrolyte synovial fluid (SF) of $\mathrm{pH} \sim 7.4$ with high-molecularweight charged biomacromolecules, supports low friction. The results demonstrate that PLs present in the SF and on the surface amorphous layer (SAL) ensure low friction in joints. The common joint dysfunction is osteoarthritis and, in most cases, accompanied by degradation of PLs bilayers, this causing that the friction coefficient was affected [11,12].

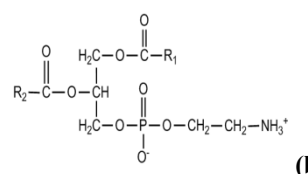

$\mathrm{R}_{-} \mathrm{CH}_{2}-\mathrm{O}_{3}-\mathrm{PO}_{4} \mathrm{H}-\mathrm{CH}_{2}-\mathrm{CH}_{2}-\mathrm{NH}_{3}{ }^{+}$(a) $\quad \mathrm{R}_{-} \mathrm{CH}_{2}-\mathrm{O}_{3}-\mathrm{PO}_{4}^{-}-\mathrm{CH}_{2}-\mathrm{CH}_{2}-\mathrm{NH}_{2} \quad$ (c)

Figure 4. Phosphatidylethanolamine (PE) a weak electrolyte, with the amino- and phosphate- functional groups is affected by solution $\mathrm{pH}$. Cationic form (at $\mathrm{pH} 1$ to 4 ), $\mathrm{pK}$ $=5.98$. Anionic form (at $\mathrm{pH} 6.5$ to 10 ), $\mathrm{pK}=2.42$; zwitterionic form, $\mathrm{pH}=4.18=\mathrm{IEP}$

\section{Conclusions}

The observations have led to the conclusions that cartilage the friction coefficient curve vs $\mathrm{pH}$ and interfacial energy of a spherical lipid bilayer curve vs $\mathrm{pH}$ is expressing amphoteric nature of phospholipidic surface with characteristic the "bell-shape curve" and isoelectric point (IEP). It was found that the interfacial energy of spherical lipid bilayers was stabilised at its lowest energy values when the $\mathrm{pH}$ varied between 6.5 and 9.5 which cover working conditions at $\mathrm{pH} 7.4( \pm) 1.5$ of natural joints. The interfacial energy vs $\mathrm{pH}$ has the "bell-shape curve" significantly dependent on $\mathrm{pH}$ is expressing cationic and anionic character of phospholipid. Most importantly shoving positive charge surface from zero $\mathrm{pH}$ of (IEP, 4.12), and negative surface charge from (IEP) to $\mathrm{pH} 12.0$.

\section{References}

1. Hills BA (1988) The Biology of Surfactant, London; Cambridge University Press.

2. Hills BA (2002) Surface-active phospholipid: a Pandora's box of clinical applications Part II Barrier and lubricating properties. Int Med J 32: 242-251. [Crossref]

3. Pawlak Z (2018) Articular Cartilage: Lamellar-Repulsive Lubrication of Natural Joints, Kindle Direct Publishing, 171.

4. Sarma AV, Powell GL, LaBerg M (2001) Phospholipid composition of articular cartilage boundary lubricant. J Orthop Res 19: 671-676. [Crossref]

5. Kosinska MK, Liebisch G, Lochnit G, Wilhelm J, Klein H, et al. (2013), A lipidomic study of phospholipid classes and species in human synovial fluid. Arthritis Rheum 65: 2323-2333. [Crossref]

6. Hills BA, Monds MK (1998) Deficiency of lubricating surfactants lining the articular surfaces of replaced hips and knees. Br J Rheumatol 37: 143-147. [Crossref]

7. Petelska AD, Figaszewski ZA (1998) Interfacial tension of the two-component bilayer lipid membrane modeling of cell membrane. Bioelectrochem. Bioenerg 46: 199-204.

8. Burke SE, Barrett CJ (2003) pH-responsive properties of multilayered poly (L-lysine) hyaluronic acid surfaces. Biomacromolecules 4: 1773-1783. [Crossref]

9. Petelska AD, Figaszewski ZA (2002) Interfacial tension of bilayer lipid membrane formed from Phosphatidylethanolamine. Biochemica Biophys Acta 1567: 79-86.

10. Petelska AD, Figaszewski ZA (2000) Effect of $\mathrm{pH}$ on the interfacial tension of bilayer lipid membrane. Biophys J 78: 812-817. [Crossref]

11. Pawlak Z, Petelska AD, Urbaniak W, Yusuf KQ, Oloyede A (2013) Relationship between wettability and lubrication characteristics of the surfaces of contacting phospholipid-based membranes. Cell Biochem Biophys 65: 335-345. [Crossref]

12. Pawlak Z, Urbaniak W, Hagner-Derengowska M, Hagner W (2015) The probable explanation for the low friction of natural joints. Cell Biochem Biophys 71: 1615-1621. [Crossref]

Copyright: (C2018 Mreła A. This is an open-access article distributed under the terms of the Creative Commons Attribution License, which permits unrestricted use, distribution, and reproduction in any medium, provided the original author and source are credited. 